\title{
THE VALUE OF MENTORING IN FACILITATING THE RETENTION AND UPWARD
}

\section{MOBILITY OF WOMEN IN ICT}

\author{
Keri Logan \\ Information Systems Department \\ Massey University, Wellington, New Zealand \\ Email: k.a.logan@massey.ac.nz \\ Barbara Crump \\ Information Systems Department \\ Massey University, Wellington, New Zealand \\ Email: b.j.crump@massey.ac.nz
}

\begin{abstract}
The low employment and poor retention of women in the Information and Communication Technology (ICT) work force remains a serious issue at a time when there is a shortage of skilled ICT workers. Effective intervention strategies such as mentoring have been found to contribute to the retention and promotion of ICT women to senior decision making positions. Using a family of concepts inherent in organisational and the ICT occupational cultures as a framework of analysis this paper presents the results from interviews with 90 professional women in the New Zealand ICT workforce regarding their mentoring experiences. Only the large Government and international organisations provided formal mentoring programs, in which 12 of the women had participated. Forty of the women had developed mentoring relationships serendipitously, usually with senior male colleagues. These relationships definitely contributed to their career advancement. A number of women wanted mentors but were unable to find them. If the industry is concerned about the lack of women in ICT then it is recommended that where formal programs are not available access to external mentoring programs should be a part of the human resources policies for ICT workers.
\end{abstract}

\section{INTRODUCTION}


With ICT being acknowledged by many governments and organisations as the key driver to economic prosperity and with the need for skilled people in large ICT projects such as those required for e-government, it is vital that all prospective talent is used. The demand for ICT professionals in New Zealand is predicted to increase steadily as government and the industry push innovative ICT as the major pathway to future prosperity (Hendery, 2006). The Government's ICT Taskforce aims to have the ICT sector contribution at 10\% of Gross Domestic Product by 2012 (Swain, 2003). Yet in 2004 the 'fill rate' for ICT professionals dropped from 89\% in 2003 to 53\% (Department of Labour, 2005). Meanwhile the number of ICT vacancies continues to increase and in May 2007 measured 1,607 (see Figure 1); a substantial number considering New Zealand's small population (Department of Labour, 2007).

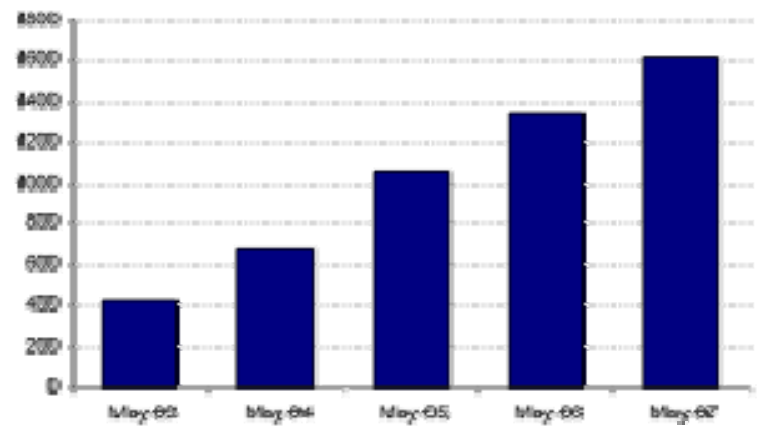

Figure 1: Department of Labour ICT Job Vacancy Programme Reports

Recognising the need for a highly skilled workforce the Taskforce identified the lack of women as an area which needs building and sustaining (ICT Taskforce, 2003). Low employment and poor retention of women in the ICT workforce has been well documented and is of concern both in New Zealand and throughout the developed world. Yet women represent a substantial pool of talent and a huge resource into which the industry could tap.

The arguments for achieving a more equitable balance of gender within IT are similar to those put forward for diversity of individuals in other male dominated fields - not just for fairness and equity, but because an opportunity cost is paid in that certain designs are not considered and therefore products are not built and processes not invented (Wulf, 1998). The consequences of not having input from women are serious as without them male perspectives will continue to dominate the way in which the technologies are developed and used and, as Wajcman (2004) writes, "unless women are in the engine rooms of technological production, we cannot get our hands on the levers of power” (p111). Thus, many rewarding careers will not be available to women and they will not be part of developing the new technologies that will impact on their lives. They will also be left out of the decision-making processes when it comes to development of, and policy-making about, technology (AAUW, 1999; UNCTAD, 2002). A further argument is that diversity in ICT teams increases creativity and innovation, both essential elements in the development of good ICT projects (Barkema, et al, 2002).

The large retrenchment suffered by the ICT industry in the early $21^{\text {st }}$ century impacted on women's retention in the industry where the lack of female mentors and career support made it difficult for women to find jobs in the industry (Cone, 2007; Bartol \& Aspray, 2006). A recent report on the ICT workforce in the United States shows a trend towards organisations increasing their ICT staffing levels (Zweig et al., 2006). But the falling working population in Western countries, attributed to the 
lower birth rate and retirement of the bubble of "baby boomers", means the numbers available for the workforce over the next few decades will substantially decrease (Feyerherm \& Vick, 2005; Schwarz, 2005). As a result many human resource departments are developing intervention programmes in an effort to encourage and retain valuable staff. Despite such proactive efforts to redress the lack of women, the percentage of women compared to men at the higher levels of ICT remains disparate. This is of concern when studies have revealed a correlation between organisational profitability and a higher level of top female representation (Greene, 2004; Feyerherm \& Vick, 2005).

Intervention strategies such as mentoring (which has long been recognised as a significant factor in retention and progression in all professional careers for both male and female employees) are one way of attracting and retaining suitable staff (Ahuja, 2002; Friday, et al., 2004; Kram, 1985; Pfleeger \& Mertz, 1995). Mentoring is said to give the protégé a better understanding of organisational politics, the gaining of reflected power and visibility, acceptance within the culture, and therefore the achievement of promotion up the managerial ranks (Headlam-Wells, 2004).

This paper draws on the results of two recent New Zealand studies that explored the nature of the ICT environment and culture, and the perceptions of the women who worked in it. The aim of the research was to increase our understanding of New Zealand's ICT work environment in which women are the minority gender. The results that this paper presents refer to the views of the women and their mentoring experience only and has the following objectives:

To investigate the nature and extent of mentoring within the ICT workplace;

To identify whether successful mentoring led to greater career opportunities.

\section{MENTORING}

Mentoring relationships are personal, reciprocal and dynamic associations whereby a "high-ranking, influential member in your environment who has advanced experience and knowledge ... is committed to providing upward mobility and support to your career” (Ragins \& Cotton, 1999, p535). The term itself is rooted in ancient Greek mythology where Odysseus committed his son Telemachus to the teachings of his friend, Mentor. Since then trusted advisers have been referred to as mentors.

Mentors can come from within or outside the protégé’s organisation, or through formal or informal arrangements. Very often those that begin informally are more effective than those that are formally arranged. Ahuja (2002) theorises that this is because interpersonal attraction may be an essential factor in successful mentoring relationships. Some research also suggests that women are more comfortable with informal relationships that have developed through friendship (Linney, 2000).

Nevertheless, formal mentoring programmes are becoming more common in the corporate world, as well as in government and non-profit sectors (Marquardt \& Loan, 2006). This is where an organisation authorises a partnership between a mentor and mentee and where the intent is understood and the objectives are clear (Linney, 2000). For example, prompted by the small number of women throughout the ICT industry Hewlett Packard introduced a formal mentoring programme within their organisation (Thorp, 2004). This programme used external rather than internal mentors because of the difficulty they foresaw in maintaining relationships due to the high international movement of their own senior staff. It has proved so successful in Australia that it is being extended throughout the Asia-Pacific region. IBM has also been proactive in supporting mentoring relationships, on a formal and informal basis, both within and outside the company. At least one other programme in New Zealand has been established specifically to encourage women in IT. 
Women in Technology (WIT), an organisation set up to support and promote women at all levels of the ICT industry, trains and provides external mentors on a formal basis for women interested in advancing their ICT careers (NZ Trade and Enterprise, 2004).

According to Johnson and Ridley (2004) outstanding mentors are selective in their choice of protégé and are careful to ensure that the "match" is suitable as they invest considerable time and energy, and emotional and professional resources encouraging, teaching and supporting them in their career. Therefore they need to ensure that the protégé has the appropriate talent, ambition and interests to make their investment worthwhile. This can, of course, lead to resentment by those who have not been chosen (Linney, 2000).

It is generally agreed that benefits accrue to both mentors and mentees. Mentors gain from being able to enhance their management skills and gain recognition from their peers. They also benefit through opportunities to network with different people and gain personal satisfaction from knowing they have helped someone else. It provides an opportunity for self-reflection and self-renewal (Marquardt \& Loan, 2006). For the protégé, the benefits of having a powerful mentor are manifold. They can provide their protégé with visibility, an advantage acknowledged as being a significant factor in progression within an organisation. This is important for women as they often do not have the same access as males to informal networks. Mentors can be powerful sponsors for their protégés, helping them to fast track through the ranks by giving them the opportunity to share, observe, discuss and learn from an experienced professional (Alboim, 2002). They can be particularly helpful through the sharing of tacit information, which leads to an understanding of the values and culture of the organisation (Marquardt \& Loan, 2006). A further important characteristic is their ability to advise them on political factors, such as who is influential within the organisation (Ragins \& Cotton, 1991).

Female mentors for female protégés are sometimes considered more suitable because of an essentialist belief they are better able to empathise and understand those difficulties pertaining specifically to women. As well, having a mentor of the same gender can make it more realistic for women to see themselves attaining similar goals. Yet the skewed gender ratios in the ICT industry means that if senior women commit to mentoring roles this places yet more pressure on them, many of whom are already precariously balancing home and work responsibilities (Lyness \& Thompson, 2000; Pfleeger \& Mertz, 1995). Generally males are considered to be more effective because of their access to formal and informal networks to which they can introduce their protégés and because they are more likely to have legitimate status and power within the organisation. This is a direct result of the well documented shortage of females in senior ICT positions and their traditional lack of access to networks and associates essential for gaining visibility and learning about the largely foreign male culture (Sernak \& May, 2003; Wajcman, 1998). For example, Wajcman (1998) believes that the "support and sponsorship from a male boss is crucial for the advancement and promotion of both men and women in organizations" (p125). On the other hand she also considers that a major "problem is that a mentoring relationship is essentially about a powerful older man identifying with a younger version of himself" and that version is usually a young male, thus females are less likely to be selected as proteges.

On a different dimension it is suggested that senior men are sometimes reluctant to enter into crossgender mentoring relationships with junior women as others in the organisation may misconstrue such an approach as a sexual advance and the innuendo accompanying this tends to demean the woman rather than the man (Ragins \& Cotton, 1999). Similarly, some women are reluctant to establish a mentoring relationship with a male, particular a powerful one (Ragins \& Cotton, 1991). Concern has also been expressed that males do not care whether or not women are gaining 
promotion to senior positions. When Pfleeger and Mertz (1995) developed an executive mentoring strategy for women and minorities in ICT they discovered that senior men "were not interested in encouraging women and minorities to move up in their organizations" (p64).

Organisational policies, and the guidance and sharing involved in mentoring are situated within a socio-cultural environment that is influenced by the occupational IT culture. There is evidence from the literature that cultural artefacts, beliefs, image and values, for example, language and esoteric knowledge requiring continual updating and learning, shape this environment. The following section discusses the multi-dimensional nature of the ICT environment.

\section{THE ICT ENVIRONMENT AND CULTURE}

One of the most widely read and replicated researchers into culture, Geertz Hofstede, collected and analysed information from people working in multi-national corporations across 66 countries. Hofstede (1980) argues that culture is historically derived and is a collection of selected ideas and their attached values which have proven to work for a particular group. It is a function of the individual and their interaction with their social environment. Every group or sub group has a common pattern of beliefs that makes up its culture and these values and beliefs affect group members' interactions according to attributes of the specific occupational subculture (Trice, 1993). The relationship of the multi-dimensions of culture are discussed by Kumar and Bjorn-Anderson (1990) who suggest that design and management choices in information systems are the result of the designers' individual values and these values are the product of the socio-cultural environment of their professional (or occupational), social and organisational context.

The notion of an occupational culture that exists within an organisational culture has only been explored by scholars in recent years. An occupational culture is independent of the particular organization and is distinguished by their members tending to emphasise what makes them similar to each other and different from others (Ogbor, 2001). Historically such cultures were often associated with blue- and white-collar workers but new occupational groups such as computer technicians or financial traders are evidence of emergent occupational cultures (Heery \& Noon, 2001). As with national and organisational cultures, occupational subcultures are not static but as Hofstede (1980) emphasises change is more likely to be at the superficial level rather than affecting the fundamental values of the group. Change is slow because these values are deeply embedded in the group psyche. Nevertheless, as different individuals move in and out of the group and the external environment changes so will the culture (Newman, 1995).

Shultz (1995) states that subcultures contain shared or non-shared webs of meaning where reality is defined as subjective and multi-dimensional, with the possibility of different meanings attached to the same phenomenon and, conversely, the same meaning may be conveyed by different phenomena. Thus there is a local creation of meaning that reflect the symbols, artefacts, social image of the ICT occupation, cultural forms, pervasiveness, consciousness of kind, extreme or unusual demands and esoteric knowledge. Further, the creation of meaning is influenced and related to gender, generation and social class and may be at odds with organisational values (Hofstede \& Hofstede, 2005).

The ICT workplace literature reports the consequences of cultural practices that reflect the values, beliefs, image, language and behaviour of members of the ICT subculture. Examples include: the poor retention of skilled personnel (Moore, 2000; Tapia, et al., 2004), the management of the sometimes extreme and unusual demands of the profession that lead to "burn out" and exhaustion (Moore, 2000; Sethi, et al., 1999) and, consequently work-life balance (Ahuja, et al., 2006; Moore, 
et al., 2006), the image of the ICT professional (Roldan, et al., 2004), the "chilly culture for women in the ICT workforce" (Faulkner et al., 2004), an examination of gender effects on the career success of information systems employees (Baroudi \& Igbaria (1994/95) and the low participation rate of women in the industry (Baroudi \& Igbaria, 1994/95; British Computer Society, 2001; Faulkner et al., 2004; Griffiths, et al., 2007; Ramsey \& McCorduck, 2005).

In most developed countries the ICT industry is disproportionately dominated by white males. In all but the lower-paid data entry levels of computing, females fail to reach a critical mass of 30 percent. The ensuing culture has evolved around masculine values (Grundy, 1996; Kiesler, et al., 1985; Spertus, 1991; Margolis, et al., 2002) and the environment is said to be one where members are insular, individualistic, competitive and anti-social (Hendery, 2006; Sproull, et al., 1984; Tapia, et al., 2004; Woodfield, 2002). Working in this type of setting is often not appealing to women whose patterns of values are said to include a preference to be more collaborative, inclusive, sharing and non-confrontational (Brush, et al., 2004; deBare, 2003). One effect of this male dominated workplace is that women often find their interests and values trivialised leaving them the options of conforming to the widespread male culture, working in an alien environment or searching for other work opportunities.

The introduction of intervention and diversity strategies, such as mentoring, can help to alleviate tensions caused through working in the male dominated ICT occupational subculture. The mentoring results from two recent studies of New Zealand ICT female professionals are presented in the next section. We begin with a description of the research design of the two studies, followed by the results. Analysis was guided by a socio-cultural framework that references organisational and occupational sub cultures that are, in turn, interpreted and informed by the mentoring literature. By using this "family of concepts" of culture (Pettigrew, 1990) we are better able to provide a frame of reference for viewing the impact of mentoring.

\section{STUDIES AND METHOD}

The mentoring data on which this paper based is derived from two studies in which 90 professional women working in the ICT industry were interviewed. The first exploratory study consisted of indepth, unstructured interviews in the city of Wellington, New Zealand with 20 women aged between 24 and 45, all of whom held responsible positions in their work place. A life story method was used whereby the women were encouraged to reflect on their working life in the industry and to voice their perceptions and experiences (Cox, et al., 1994). It was felt necessary for the participants to have the freedom to shape their own accounts and to reflect on their relationships and histories that had influenced their careers in ICT. These unstructured interviews allowed the women to express themselves in their own way, at their own pace and emphasised the importance of understanding the context in which events take place. A snow-ball sampling system was used (Trochim, 1999). This is a technique whereby interviewees are asked to recommend further participants from their acquaintances, thus the sample appears to grow like a snowball. Although participants may recommend friends and associates with similar views to their own, thus potentially creating a biased sample, it was considered an appropriate method for this study. Bias could be offset by giving participants freedom to express their views through the types of interview adopted. Therefore, interviews were initially undertaken with acquaintances and friends in the industry who then referred the researchers to other women working in similar areas.

Seventy women, aged between 23 to 61, from Auckland, Wellington, Christchurch and Dunedin, New Zealand's four major cities, were interviewed. Again, all the women worked in skilled to 
highly skilled areas of the ICT industry, in a variety of occupational sectors. Funded by a grant from the Society for Research on Women, the New Zealand Computer Society (NZCS) and the Women in Technology (WIT) group advertised the details on their web sites. Most of the women contacted the researchers via email after visiting these sites.

Prior to the interviews the women were asked to fill out a form giving demographic information regarding age, salary range, and type and size of organisation. A checklist of questions that reflected themes from the IT professionals' literature and results from the first study was devised by the interviewers. The themes included Entry into IT, Employment Practices, the Cultural Image of Computing, Mentoring and The Future. These served as a focus for the interviews yet did not constrain the women from the freedom to discuss issues they felt were important and relevant. The intent was to allow the women to speak for themselves, giving their own perspectives from their own experiences. Therefore the checklist was used as a guideline to ensure the required topics were covered with all interviewees. The first question all the women were asked was how they began their ICT careers. In answering this question the women invariably brought up other associated issues. For example, after explaining that the high salaries was the main driver for choosing a career in ICT, one woman then began discussing the difficulties of women working in a male dominated environment. She felt men and women needed different support networks around them, and that "the talk is quite different when groups of males get together from when groups of females get together - they will slip into male ways of talking with lots of swearing, every second word is a swear word". For another woman the same question led into a discussion about ICT recruitment policy and equity at her present work place.

In order to minimise the potential for bias a minimum of two interviewers attended all interviews in both studies. These were audio-taped (after ensuring that the interviewees were agreeable) and transcribed within a week of each interview. Patton's (1990) suggestions for content analysis guided the identifying, coding and categorising of the primary patterns in the verbatim transcripts. Analysis was informed by the "family of concepts" (Pettigrew, 1990) inherent in organisational and ICT occupational cultures and framed by seeking answers to the questions:

1. How did mentoring facilitate enculturation into the ICT occupational subculture?

2. Are formal mentoring programmes a positive strategy for challenging the ICT occupational subculture?

3. Did mentoring progress careers and provide confidence?

4. Does a mentor's gender affect the mentoring outcomes for women?

5. What are the difficulties in finding a mentor?

The headings for the following Results Section relate to these questions which are derived from the content analysis that reflects the major concerns and interests that the women expressed about mentoring.

\section{RESULTS}

Fifty two of the 90 interviewees claimed to have had a mentor during the course of their working life. They variously described their mentor as 'friend', 'confidant', 'guide', 'a wise man'. Their descriptions fit Ragins and Cotton's (1999) definition of a mentor as a senior and experienced member of an industry who supports, guides, offers practical help, and brings wisdom and constructive ideas to a younger, inexperienced member. The women were asked if they believed mentoring helped their enculturation into the ICT occupational subculture and to describe the outcome. 


\section{Enculturation into the ICT occupational subculture}

Understanding the common patterns of values and beliefs held by the members of the ICT subculture and the wider organisation was recognised by many women as critical to negotiating office politics. Jane appreciated the role her mentor played in helping her understand and be accepted into the culture of both the organisation as a whole and the ICT department in particular and her comments corresponded with many of the other women in that:

It was all about handling the politics, which is the key, key thing. Who are the important people, who are the people whose opinion really matters and how do you nurture and make, build and nurture relationships with those people. What to do with the tricky HR type issues or non-performers. Career decisions. He helped me a lot with organisational culture and introduced me to a lot of people which was excellent.

Jane's mentor provided a gateway into understanding the patterns or systems of values that Hofstede and Hofstede (2005) term "mental programmes" and which they note as being shared with some but not with other people. His ability to advise her on political factors was recognised by Jane as a critical and positive feature of her mentor's guidance; identified by Ragins and Cotton (1991) as a very important contribution.

Gaining visibility through having a high profile mentor was another important factor in the enculturation process. Wajcman (1998) highlights this when she states that visibility, acceptability and networking go hand in hand. The advantage of being mentored by a senior, experienced sponsor who shares tacit information that leads to an understanding of the values and culture of the organisation and group (Marquardt \& Loan, 2006) proved to be a valuable and supportive experience for Wilma. Wilma purposely chose a man in his 50's to be her mentor to help her deal with male staff whom she felt were circumventing her because she was female and therefore not acceptable as their manager.

$\mathrm{He}$ is an older experienced gentleman because I can get into quite aggressive relationships when staff are questioning me as the decision maker. I chose him specifically to guide me through some of those, the politics and culture and his experience in all of that. Because I see that quite strongly as in when they [staff] first meet you and they are sort of questioning as if "are you really the manager" While they reported directly to me they were always trying to get around to the big kahuna [the CIO] to whom only I reported. He has been invaluable guiding me through that.

\section{Formal programmes}

Increasing numbers of organisations are implementing diversity programmes that include policies on non-discrimination, inclusion of people with a disability, work-life balance, cultural diversity and mentoring. The women were asked if their organisation offered a formal mentoring programme and their responses revealed that 7 out of the 68 companies in which these women worked had a formal system in place. The companies were all large multi-national or government organisations and the schemes were mainly for new employees to ease them into the job and facilitate their productivity as quickly as possible. Nine of the 12 women who worked for these organisations had found the mentoring useful. Typical of their responses is the following from Anita:

When they asked me to come into the IS structure, yes I had a mentor assigned formally then. I think it is a very important part, coaching and mentoring and providing that for people if you are expecting them to shift or change what they are doing or wanting to accelerate their progress. I have got three people assigned to me now. So no I believe in it very strongly. 
Anita acknowledged the value the mentoring programme had in the enculturation process and as a support when she joined "the IS structure". She recognised that the way a person behaves in a group has more to do with the group than the individual. Anita's mentor eased the "fit" and the interaction between the person and their socio-cultural environment thus causing the adaptation of the behaviour of the individual to fit those of the collective .

For some of the women such formal programs were not practicable or flexible enough to accommodate some individual circumstances. For example, Jaquie explained why she had not become involved in the program:

We do have a mentoring policy in this organisation, but I think because, well first I worked from home for such a long time and then I worked for a client at their site and I have missed out on a lot of the things that probably I shouldn't have in that way. I'd say no, I haven't really been mentored, and yes it would have been good.

This highlights two points. First, working from home or teleworking is often recommended as a way of addressing the difficulties women in ICT face in balancing home and work responsibilities, yet in such situations it is difficult to develop a mentoring relationship. An alternative is to conduct the relationship via the Internet which requires commitment by both parties. Second, it is common for ICT workers to be sent to client sites for lengthy periods and this also tends to act negatively on the formal mentoring programmes. Mentors are usually senior members of the organisation and therefore 'time scarce', and unless the protégé is proactive in such situations the contract is almost certain to break down.

Joan works in an organisation where it is the policy for all senior members to mentor graduates as part of leadership development. She believed the formal mentoring program had never worked for her, saying "I did have a mentor in senior management but I could never meet up with him because he was either too busy or not available". Her comments about mentoring are mixed as she did "not really like mentoring people much". She stated:

What do you tell them? When I mentor people I usually try and help sort out their personal problems rather than their work things, things that are affecting their lives

... actually I have a graduate that I am supposed to be mentoring this year and I haven't done anything with her, which is really poor isn't it?"

Joan's comment on sorting “out their personal problems” reflects her psychosocial approach by providing counselling but her ambivalence about the usefulness of mentoring obviously impacts negatively on her own mentoring duties. Her belief that the mentee "should drive the process - if they want to put some time into it and push you to meet with them then I will always meet with them" may not be suitable for all mentees, especially a new graduate. While this attitude may be satisfactory for those who have the confidence to drive the process, as a young woman working in a male dominated environment it is not always easy to be forceful with a senior member of staff. No doubt there are other mentors with similar perceptions as to the value of mentoring and without total buy in of the staff involved the objectives of the scheme would be somewhat diminished. Kram and Isabella (1985) state that it is necessary for a mentoring relationship to be vital and significant if both individuals are to benefit from the experience. To ensure positive outcomes they note that there needs to be complementarity of needs that will then propel it forward to the cultivation phase where effectiveness is maximised. An organisation that implements a mentoring programme must therefore ensure that mentors and mentees perceive benefits from involvement in the scheme.

\section{Career development and confidence}

Reflecting on their experiences many of the women believed that their mentor had been critical in helping them advance their careers. Most of the mentoring relationships were formed 
serendipitously, usually because a senior male identified the woman as having potential and took a greater than usual interest in her. For example, Julie a very successful and senior ICT professional, was mentored by an internationally renowned programmer when she joined a specialised ICT company as a young, and the sole, female in her division. Her mentor singled her out as his protégé and Julie attributes her success in the ICT profession to the time and energy that he invested in her. Johnson and Ridley (2004) point out that outstanding mentors carefully select their protégé and Julie's experience is an example of this. His belief in her abilities gave her confidence, she said, to attempt many other things. They also developed a special friendship which continued until he died. Friendship and respect were two of the major components many of the women noted of their successful relationships. Elements of the following quote from Julie were evident in the accounts of other interviewees:

He took me under his wing and gave me games to play and things to figure out and stretched me and really wanted to make me into something that was a singing, dancing version of consulting. He saw some of the same sparks as were in himself I think - he was very dry, very internal sort of focus, very nice. Then they sent me to America when I was 21 and because he assumed I could do it, so did I.

Wajcman's (1998) observation that “a powerful older man” invariably selects a younger, male version of himself is confirmed in one respect. Julie believed that he "saw some of the same sparks as were in himself” and, notwithstanding her gender, was prepared to guide, mentor and progress her career. Julie's close relationship with her mentor nurtured her development and career by guiding her growth within the ICT socio-cultural environment and contributed to sense-making of her participation within that world and various aspects of herself such as confidence (Jenks, 1983).

Similarly Mary, now a high profile woman in the ICT industry explains:

Yes numbers of mentors and all men, which is interesting isn't it. A couple of them have died which has been a bit sad, but people like [name not given] he sort of gave me, like a chance. I had this wonderful project proposal and he said to me if you have the energy to make it last, make it fly. You never forget that do you. He just took a punt.

Situations arose where clients assumed that male colleagues were the manager and ignored the woman who was the manager or male colleagues ignored the women's ideas at meetings, yet when a male repeated them they were considered his ideas. Such invisibility was a recurring problem for many. The ability to talk through these problems with a mentor consistently led to successful solutions. Problems such as invisibility are inherently socio-cultural and are connected to underlying beliefs and images of the ICT professional as male. Gaining visibility and support through having a high profile mentor was an important factor in negating the norms of the ICT occupational culture within which these women worked.

\section{Female versus male mentors}

Understandably, given the skewed gender balance in IT, most of the mentors were male. Margaret, who had unsuccessfully sought a female mentor, believed that apart from the small number of senior women in the industry, many were "not interested [in becoming mentors] as they don't have the time with all their other responsibilities". The women did not consider the predominance of male mentors a problem and emphasised that the most important factor was having someone they could respect, who could give appropriate advice and who had good attitudes and approaches. They also appreciated the fact that because their mentors were experienced ICT professionals and had large networks of contacts they were able to provide visibility, as well as help them understand the 
culture and deal with the different ways in which males and females tended to operate in the ICT workplace.

Nevertheless, some spoke about the differences in relationships between male and female mentors and how sometimes it was better to have a female who could understand their uniquely female issues and problems. Merle, for example, observed that:

It is nice to sit down and talk with them [females]. You can relax a bit more and bring in other issues. With a male you'd probably just sit there and talk about work and that's it.

Mary also spoke about some of her "very strong minded" friends losing confidence after being absent from the work force through parental leave and believed that for women returning to the ICT workforce, after even a short absence, a female mentor who has been in a similar situation and survived, could have a huge impact on their retention. This was confirmed by Judith who discovered that her female mentor:

... could understand my problems with working, pregnancy and having a small child.

She reassured me that the awful time would go and that I just had to hang in there - it was ok, possible to work and have my family.

Although it is generally accepted these days that women have careers, the assumptions that maintain the gender specific division of labour around family and home responsibilities remain largely unchallenged leaving women the predominant caregivers. Striking a balance between work and home responsibilities is a worry to many women (Bartol \& Aspray, 2006) because of the need to work difficult hours and maintain currency in a rapidly changing technological world. A number of the younger interviewees (30-40) expressed concern about their ability to continue working in ICT if they had children. While not suggesting that all females have identical problems, or are even more empathetic towards domestic and family situations, in some circumstances female mentors may be more appropriate, even though they may not have the same status and power of their more senior male colleagues.

\section{The difficulties of finding a mentor}

At least a dozen women were desperate to find a mentor but had found it difficult. One interviewee had approached seven people before finding a person who agreed to be her mentor. Reasons for desiring such an alliance were loneliness, a need for a support structure, receiving good advice and “just working out a way [into the group]". Lianne's account of her feelings demonstrates one effect of being a minority. She is not concerned about sexual harassment but suggests that it is this fear from her male colleagues which creates a barrier to more collegial and supportive working relationships.

Because particularly now, I guess, I feel quite left to my own devices really at work. I'm not isolated because there are a lot of other people within the industry. But I have no-one who understands what I am doing. I haven't ever had a mentor. And you know it is a very dry business relationship. I think they are scared to know me closer because you know they might get sexual harassment or something. And we never meet outside work. I think if there were more women in my area that work with me quite possibly we would have a slightly warmer relationship.

Commenting on what she would do differently if she had her time again, Barbara, a mature woman running her own consultancy, explains:

One of them is finding mentors. I never really had a mentor and I think that is something I'd benefit from, and I don't quite know how you do that. And it's ridiculous really because I am a good networker. And so getting some good advice, 
good support and just working out a way in, I never really worked out a way in at [last place of work]. And maybe some of that is a girly thing as well, about the confidence to actually ask for it.

The comments of these women reflect the isolation some women experience working in a sociocultural environment where males are the dominant gender and consequently the masculine norms and values of the occupational ICT culture is gendered male (Moore et al., 2006; Tapia \& Kvasny, 2004). One woman said "if I could get one now [mentor] I would be more inclined to stay" indicating that having a mentor may be a significant factor in female retention. In an attempt to overcome this isolation a number of the women belonged to WIT and were participating in their formal mentoring scheme, both as mentors and mentees.

\section{CONCLUSIONS}

ICT remains one of the few sectors where men significantly dominate the work force (Hendery, 2006). Consequently, outdated patriarchal attitudes continue to influence and define the social system (Hofstede, 1980) as indicated by the women's complaints about being invisible. Therefore it has been useful to view the data through a "family of concepts of culture" (Pettigrew, 1990) that includes organisational culture and the ICT occupational culture with its values and behaviours dictated by the majority, male group.

The retention and promotion of women in the ICT environment is a complex issue. Obviously mentoring is not the only means of leveraging their opportunities, but for those who have the good fortune to become involved in mentoring relationships the consequences are highly beneficial. It is clear that good mentoring facilitates upward mobility yet most of the mentoring relationships were informally developed. These results reinforce previous research (ie that having an experienced and senior person as a mentor gives the employee a number of benefits). They have helped their protégés gain the confidence to take on difficult projects; they have extended their knowledge, given them visibility, supported them in difficult situations, guided them through tricky management situations and taught them how to deal with the more covert political aspects of their workplace. They have also provided them with opportunities to network and make the contacts which are so important to gaining promotion. It is this interaction between the protégé and their social environment that gains them acceptance in the ICT work place.

Why then, do so few New Zealand companies offer formal mentoring schemes for their ICT employees? Is it because the successful relationships are those that are formed on a casual basis through recognition of ability and mutual respect? Is it because mentoring is not considered necessary by the organisation? Is it because top management is generally male and therefore they do not consider a need to focus on developing female talents. Or is it, as Ahuja (2002) posits, that formal mentoring schemes do not match personalities satisfactorily and therefore are not successful? In the end it may be that interpersonal attraction is the critical success factor in such relationships. Interpersonal attraction certainly was a major factor in the development of many of these women's mentoring relationships.

The results and analysis of the 90 interviews have identified both positive and negative aspects of mentoring from which the following recommendations are made:

1. Ensure formal schemes involve commitment by both mentor and mentee. 
When providing a formal mentoring scheme it must be seen to be supported by senior management, and implemented in a positive manner. While there may be an expectation for senior employees to act as mentors, participation should be voluntary. Feed-back mechanisms should be put in place to ensure that both parties are suitably matched and result in constructive outcomes. There should be a guarantee that the mentor will be willingly available on a regular basis and a clear outline of the intent and objectives. However, the nature of the relationship must be defined by the participants and the mentor must take into account the needs of the mentee.

\section{Encourage and facilitate informal mentoring relationships}

If a formal scheme is not considered viable, then the ICT department should encourage female staff to form such relationships outside of the workplace, within organisations such as WIT and the Computer Society. Such organisations offer mentoring opportunities for their members for a relatively small payment. They spend considerable time in matching mentors with mentees so that satisfactory outcomes are produced. As well, they provide their members with opportunities to network and meet with influential and experienced ICT professionals. They have regular breakfast, lunch and evening meetings with guest speakers and provide time for members to interact and get to know each other. Such informal activities encourage the development of networks and contacts that may be available to act as informal mentors. This would be particularly useful for those women who found it difficult to strike a mentoring relationship yet felt an overwhelming need for some sort of guidance and support, particularly when a feeling of aloneness was the reason. These feelings originate from standing apart from the dominant group.

3. Provide an inclusive and responsive mentoring scheme

For part-time and teleworkers who encounter administrative difficulties in developing a mentoring relationship, encourage participation in e-mentoring schemes. Women in ICT are already fluent in their use of computers and comfortable with using the Internet. Many use chat rooms and women's lists for other purposes. There are now a variety of excellent ementoring schemes and ICT departments should encourage their female staff to participate in such schemes as a way of managing their careers and promotion. E-mentoring schemes do not make the women more visible within their organisation or local community, or raise their profile. Nevertheless they do provide a degree of support and advice and thus contributes to alleviating some of the sense of "aloneness" that the women who wanted a mentor expressed.

Finally, regarding those women who unsuccessfully tried to attract a mentor, there are several questions that need to be asked. Was their lack of success because the men did not see them as a good "investment"? And if so, was this because they were female and not in their own male image?

\section{REFERENCES}

American Association of University Women (1999) Gender Gaps. Where schools still fail our children, Marlowe \& Company, New York.

Ahuja, M.K. (2002) "Women in the information technology profession: a literature review, synthesis and research agenda”, European Journal of Information Systems, Vol 11 No 1, pp 20-34.

Ahuja, M., K., Chudoba, K., M., Kacmar, C., J. \& McKnight, D. H. (2006) “IT road warriors: Balancing work-family conflict, job autonomy, and work overload to mitigate turnover intentions”, MIS Quarterly, Vol 30 No 3, pp 1-18. 
Alboim, N. (2002) Fulfilling the promise: Integrating immigrant skills into the Canadian economy, Caledon Institute of Social Policy, Ottawa.

Barkema, H.G., Baum, J.A. \& Mannix, E.A. (2002) “Management challenges in a new time”, Academy of Management Journal, Vol 45 pp 916-930.

Baroudi, J.J., \& Igbaria, M. (1994/95) “An examination of gender effects on career success of information systems employees”, Journal of Management Information Systems, Vol 11 No 3, pp 181-102.

Bartol, K.M. \& Aspray, W. (2006) “The transition from the academic world to the IT workplace” in J. McGrath-Cohoon \& W. Aspray (Eds.), Women and Information Technology. Research on Underrepresentation (pp. 353-377, The MIT Press, London.

British Computer Society. (2001) “IT employment: Gender bias in IT - the insoluble problem?”. http://www.bcs.org.uk/review/2001/html/p237.htm accessed 9 October 2001.

Brush, C.G., Carter, N.M., Gatewood, E., Greene, P.G., \& Hart, M.M. (2004) Clearing the hurdles: Women building high-growth businesses. NJ: Pearson Education, Upper Saddle River.

Cone, E. (2007) "Why do women leave IT” CIO Insight”. http://www.sioinsight.com/print_article2/0,1217,a=209724,00.asp accessed 27 June 2007

Cox, A., Dickinson, H. \& Parsons, V. (1994) “Gender and computing in further education: A life story approach” The Vocational Aspect of Education, Vol 46 No 3 pp 297-305.

deBare I. (2003) "High-tech industry zipping along, but women often are left behind. Women in computing, Part 1”. http://www.sacbee.com/static/archive/news/projects/women/wcm accessed 12 November 2003.

Department of Labour (2005) "Information technology professional: Occupational skill shortage assessment”. http://www.dol.govt.nz/publications/jvm/professionals/2005/ict.asp accessed 27 June 2007.

Department of Labour (2007) “Findings from the Information Technology recruiters survey 2006” http://www.dol.govt.nz/publications/jvm/recruit/2006/summary.asp accessed 27 June 2007.

Faulkner, W., Sørensen, K., Gansmø, H., Rommes, E., L. Pitt, Berg, V. L., et al. (2004) “Gender inclusion within the ICT workforce” http://www.sigis-ist.org: accessed 29 August 2007.

Feyerherm, A. \& Vick, Y. (2005) “Generation X women in high technology. Overcoming gender and generational challenges to succeed in the corporate environment", Career Development International, Vol 10 No 3, pp 216-227.

Friday, E., Friday, S.S. \& Green, A.L. (2004) “A reconceptualization of mentoring and sponsoring”, Management Decision, Vol 42 No 5, pp 628-644.

Greene, K. (8 November 2004) "Women at the top - a smart move”, The Dominion Post, C4.

Griffiths, M., Moore, K., \& Richardson, H. (2007) “Celebrating heterogentity? A survey of female professionals in England”, Information, Communication \& Society, Vol 10 No 3, pp 338357.

Grundy, F. (1996) Women and Computers. Whittshire: Cromwell Press.

Headlam-Wells, J. (2004) “E-mentoring for aspiring women managers”, Women in Management Review, Vol 19 No 4, pp 212-218. 
Heery, E., \& Noon, M. (2001). A dictionary of human resource management. Oxford: Oxford University Press.

Hendery, S. (2006) “IT grappling with image problem”, The New Zealand Herald, http://www.nzherald.co.nz/section/story.cfm?c id=5\&objectid=10390657 accessed 13 July 2006.

Hofstede, G. (1980) Culture's consequences. International differences in work-related values, Sage Publications, New Delhi.

Hofstede, G. \& Hofstede, G.J. (2005) Culture and organizations. Software of the mind, McGrawHill, NY.

ICT Taskforce (2003) Breaking through the barriers, http://www.nzte.govt.nz/common/files/ictfinal-report.pdf accessed 15 July 2003.

Jenks, J. A. (1983). The mystery of women's early adulthood. Clinical Social Work Journal, Vol 11 No 1, pp 52-63.

Johnson, W. \& Ridley, C. (2004) “The Elements of Mentoring”, Palgrave Macmillan, NY.

Kiesler, S., L. Sproull and J. Eccles (1985) "Pool halls, chips and war games: Women in the culture of computing." Psychology of Women Quarterly, Vol 9 No 4, pp 451-462.

Kram, K.E. (1985) Mentoring at work: Developmental relationships in organizational life, Scott Foresman, Glenview, Ill.

Kram, K.E., \& Isabella, L.A. (1985) "Mentoring alternatives: The role of peer relationships in career development”, The Academy of Management Journal, Vol 28 No 1, pp 110-132.

Kumar, K., \& Bjorn-Anderson, N. (1990) “A cross-cultural comparison of IS designer values”, Commuinications of the ACM, Vol 33, No 5, pp 528-538.

Linney, B.J. (2000) “Mentoring: women learning from others”, Physician Exec, Vol 26 No 1, pp 7275

Lyness, K.S. \& Thomson, D.E. (2000) “Climbing the corporate ladder: Do female and male executives follow the same route?” Journal of Applied Psychology, Vol 85 No 1, pp 86-101.

Margolis, J., \& Fisher, A. (2002) Unlocking the clubhouse: women in computing, MIT Press, Cambridge, MA.

Marquart, M.J. \& Loan, P. (2006) The Manager as Mentor, Praeger Publishers, Westport, CT.

Moore, J. E. (2000) “One road to turnover: An examination of work exhaustion in technology professionals”, MIS Quarterly, Vol 24 No 1, pp 141-168.

Moore, K., Grifiths, M., \& Richardson, H. (2006) "Moving in, moving out? A survey of women in ICT”, Paper presented at the Symposium on Gender and ICT: Women for Change.

NZ Trade and Enterprise (2004) New programme to ensure women get ICT opportunities, http://www.nzte.govt.nz/display404.aspx accessed 11 November 2004.

Newman, J. (1995) “Gender and cultural change”, in C. Itzin \& J. Newman (Eds.), Gender, culture and organizational change: Putting theory into practice, pp. 11-29, Routledge, London.

Ogbor, J.O. (2001) “Critical theory and the hegemony of corporate culture”, Journal of Organizational Change Management, Vol 14, No 6, pp 590-608. 
Pettigrew, A. (1990) Conclusion: Organizational climate and culture. In B. Schneider (Ed.), Organizational climate and culture (pp. 413-434). Jossey-Bass, San Francisco.

Patton, M.Q. (1990) Qualitative evaluation and research methods, Sage Publications, California.

Pfleeger, S.L. \& Mertz, N. (1995) “Executive mentoring: what makes it work?” Communications of the ACM, Vol 38 No 1, pp 63-74.

Ragins, B. R. \& Cotton, J. L. (1991) "Easier said than done: Gender differences in perceived barriers to gaining a mentor”, Academy of Management Journal, Vol 34 No 4, pp 939-951.

Ragins, B.R. \& Cotton, J.L. (1999) "Mentor functions and outcomes: A comparison of men and women in formal and informal mentoring relationships”, Journal of Applied Psychology, Vol 84 No 4, pp 529-550.

Roldan, M., Soe, L., \& Yakura, E. K. (2004) "Perceptions of chilly IT organizational contexts and their effect on the retention and promotion of women in IT", paper presented at the Proceedings of the 2004 SIGMIS conference on computer Personnel Research Careers, culture and ethics in a networked environment, Tucson, AZ.

Schwarz, R. (August 1, 2005) "Harvesting years of experience”, The Dominion Post, C4.

Sernak, K.S. \& May, J.P. (2003) Conversation and voice; Feminist mentoring for social and political change, Advancing Women, http://www.advancingwomen.com/awl/spring2003/ accessed 24 July 2004.

Sethi, V., Barrier, T., \& King, R. C. (1999) "An examination of the correlates of burnout in information systems professionals”, Information Resources Management Journal, Vol 12, No 3, pp 5-13.

Shultz, M. (1994) On studying organizational cultures: diagnosis and understanding, de Gruyter, Berlin.

Spertus, E. (1991) “Why Are There so Few Female Computer Scientists?” MIT, Available by public FTP at: ftp.ai.mit.edu/pub/ellens/wp-womcs.zip accessed 20 July 2004.

Sproull, L.S. Kiesler, S.B. \& Zubrow, D. (1987) “Encountering an alien culture”, in S.B. Kiesler and L.S. Sproull, (Eds.), Computing and change on campus, pp 173-194, Cambridge University Press, Cambridge [Cambridgeshire], NY.

Stapley, L.F. (2006) Individuals, groups, and organizations beneath the surface, H. Karnac (Books) Ltd, London.

Swain, P. (2003) "Government responds to ICT taskforce” http://www.beehive.govt.nz/ViewDocument.aspx?DocumentID=18249 accessed 15 May 2004.

Tapia, A.H., \& Kvasny, L. (2004) "Recruitment is never enough: Retention of women and minorities in the IT workplace”, paper presented at the Proceedings of the 2004 SIGMIS conference on Computer personnel research: Careers, culture, and ethics in a networked environment, Tucson, AZ.

Tapia, H. Kvasny, L. \& Trauth, E. (2004) "Is there a retention gap for women and minorities? The case for moving in versus moving up”, in M. Igbaria and C. Shayo (Eds.), Strategies for Managing IS/IT Personnel, Idea Group Publishing, London.

Thorp D. (2004) HP big on mentoring women, Australian IT Today Media Monitors, Vol 33. 
Trice, H.M. (1993) Occupational subcultures in the workplace,ILR Press, Ithaca, NY.

Trochim, W.M. (1999) Research methods knowledge base, ProQuest database on the World Wide Web, http://trochim.human.cornell.edu/kb.sampnon.htm accessed 13 December 1999.

United Nations Conference on Trade and Development (2002). E-Commerce and Development Report 2002, United Nations, New York.

Wajcman, J. (1998) Managing like a man: Women and men in corporate management, Polity Press, Cambridge.

Wajcman, J. (2004) Technofeminism, Polity Press, Cambridge.

Woodfield R. (2002) “Woman and information systems development: not just a pretty (inter)face?” Information Technology \& People, Vol 15 No 2, pp 119-138.

Wulf W.A. (1998) “Diversity in Engineering”, The Bridge, Vol 28 No 4, pp 1-7.

Zweig, P. Kaiser, K. Beath, C. Bullen, C. Gallagher, K. Goles, T, Howland, J. \& Simon, J. (2006) “The Information Technology Workforce: Trends and Implications 2005-2008” MIS Quarterly Executive, Vol 5 No 2, pp 101-108 
